PAPER

\title{
Surgery for drug resistant partial epilepsy in children with focal cortical dysplasia: anatomical-clinical correlations and neurophysiological data in 10 patients
}

\author{
S Francione, P Vigliano, L Tassi, F Cardinale, R Mai, G Lo Russo, C Munari
}

J Neurol Neurosurg Psychiatry 2003;74:1493-1501

See end of article for authors' affiliations

Correspondence to Dr Stefano Francione, Centro per la Chirurgia dell'epilessia "Claudio Munari", Dipartimento di Neuroscienze, Ospedale Niguarda $\mathrm{Ca}^{\prime}$ Granda, Pz Ospedale Maggiore 3, 20162 Milan, Italy; epsur@mailserver.unimi.it

Received 7 July 2002 In final revised form 27 March 2003

Accepted 8 May 2003

\begin{abstract}
Objective: To analyse a population of children with focal cortical dysplasia operated on for drug resistant partial epilepsy, with emphasis on clinical features, seizure semiology, interictal and ictal EEG and stereo EEG findings, histological and topographical characteristics of the lesions, extension and localisation of cerebral excision, and its postoperative effect on seizure frequency.

Methods: 10 patients were studied, aged between 26 months and 11 years (median 6 years). Magnetic resonance imaging (MRI) abnormalities were unilobar (temporal 3, frontal 2), bilobar (2), or multilobar (1); the two patients with negative MRI suffered from frontal seizures. Presurgical diagnostic steps varied in complexity and invasiveness depending on the anatomical/electrical/clinical features of each patient. In four patients they included only scalp video EEG monitoring, and in six, also invasive recordings using stereotactically implanted intracerebral electrodes. Surgery consisted of corticectomy plus lesionectomy in all cases.

Results: $70 \%$ of the patients were seizure-free after a minimum postoperative follow up of 25 months. These included three patients with temporal lesions and four of seven patients with other lobar or multilobar extratemporal localisation. One patient had improvement in seizure control. Outcome was poor in multilobar patients, but a class la outcome was obtained in one case after partial lesionectomy associated with bilobar corticectomy. All patients showed developmental improvement.

Conclusions: Analysis of the data in these patients allowed the production of an "anatomical-clinical concordance" list, which appeared to be correlated with the diagnostic steps performed. Carrying out a stereo EEG exploration in the most complex cases proved useful in defining the epileptogenic zone in extratemporal and multilobar epilepsies. Stereo EEG recordings facilitated a tailored resection of extralesional cortex.
\end{abstract}

$\mathrm{S}$ urgical treatment for drug resistant partial epilepsy may be an early option in childhood because it offers the possibility of achieving a definitive cure, preventing cognitive deterioration, and enhancing the overall quality of life and psychosocial adaptation. In childhood, a malformation of cortical development is found in $14 \%$ of cases of drug resistant partial epilepsy and it accounts for $18-26 \%$ of all histological diagnoses in paediatric epilepsy surgery series. ${ }^{1-3}$ The epileptogenic role of cortical malformations and the possibility of good seizure control after their complete removal are well documented. Seizure-free outcome is said to be better with the complete excision of the cortical dysplasia than with incomplete excision. ${ }^{45}$ A positive outcome is likely if a discrete lesion is found and if it does not involve functionally eloquent cortex. ${ }^{4}$

Magnetic resonance imaging (MRI) techniques have substantially improved the evaluation of epileptic patients in recent years, particularly in children with malformations of cortical development. ${ }^{167}$ However, limits in delineating the precise extension of the malformation have been pointed out. ${ }^{2-11}$ As a result it has been suggested that neurophysiological techniques should be employed for a better definition of the epileptogenic zone. ${ }^{12}$ In children particularly, chronic subdural electrodes, ${ }^{13}$ mixed techniques, ${ }^{35}$ and stereo electroencephalography $(E E G)^{14}$ have been employed successfully.

In this study we present a population of children with focal cortical dysplasia operated on for drug resistant partial epilepsy, our aim being to describe the general clinical features, seizure semiology, interictal and ictal EEG, and stereo EEG peculiarities. These data were correlated with histological and topographical characteristics of the lesions, principally with the extension and localisation of the cerebral excision and its postoperative effect on seizure frequency.

\section{METHODS}

We studied 10 consecutive patients under 16 years of age affected by severe drug resistant partial epilepsy and operated on in the Epilepsy Surgery Centre "C Munari" in Milan between May 1996 and September 2000. They were all identified as having a focal cortical malformation on the basis of histological examination.

The general characteristics of the patients are given in table 1 . There were five girls and five boys, and their age at the time of surgery ranged from 26 months to 11 years (median 6 years 3 months). Six patients had either a family history of epilepsy or febrile convulsions. Eight patients had several seizures a day; one had daily seizures and one had weekly seizures. Only two had a seizure-free period of any length (three years in one and six months in the other), while two patients had experienced frequent epileptic activity.

Seven patients were right handed, one was left handed, and the remaining two were ambidextrous. In seven patients neurological examination was negative; one (case 8) had congenital hemiparesis and another (case 4) developed mild right hemiparesis with dysarthria after prolonged status epilepticus. A 2 year 7 month old girl (case 6) had choreic 
Table 1 Seizure semiology and findings on magnetic resonance imaging

\begin{tabular}{|c|c|c|c|c|}
\hline Patients (age at surgery) & $\begin{array}{l}\text { Age at seizure } \\
\text { onset }\end{array}$ & Aura & Seizure characteristics & MRI findings \\
\hline Case 1 (7 y $3 \mathrm{~m})$ & $20 \mathrm{~m}$ & Sensation in stomach & $\begin{array}{l}\text { Psychomotor arrest, staring, } \mathrm{R} \text { deviation } \\
\text { of eye and trunk, facial expression of } \\
\text { fear, oro-alimentary automatisms, } \\
\text { vegetative signs, rigidity of both arms }\end{array}$ & L temporal pole atrophy with blurring \\
\hline Case $2(4$ y) & 1 y $10 \mathrm{~m}$ & No & $\begin{array}{l}\text { Psychomotor arrest, staring, } \\
\text { unresponsive, oro-alimentary } \\
\text { automatisms. At the end she says } \\
\text { "how disgusting" and tries to vomit } \\
\text { Eye and head deviation to R, } \\
\text { moan, apnoea, R blinking, limb rigidity }\end{array}$ & $\begin{array}{l}\text { Slight cortical thickening with blurring of } \\
\text { R temporal pole and T3-T5 gyrus }\end{array}$ \\
\hline Case $3(9$ y) & 8 y $4 \mathrm{~m}$ & No & $\begin{array}{l}\text { Continuous activity, L blinking, L face } \\
\text { tonic, discrete R arm automatisms, } \\
\text { frightened }\end{array}$ & $\begin{array}{l}\text { Large white matter abnormality in } \mathrm{R} \\
\text { temporal pole, and posterior; Ammon } \\
\text { horn cyst }\end{array}$ \\
\hline Case $4(3$ y $8 \mathrm{~m})$ & $10 \mathrm{~m}$ & No & $\begin{array}{l}\text { Fixed eyes, R face and arm clonic, } R \\
\text { arm clonic } \\
\text { Epileptic status }\end{array}$ & $\begin{array}{l}\text { Cortico-subcortical signal alteration and } \\
\text { cortical thickening in L frontal operculum } \\
\text { and insula }\end{array}$ \\
\hline Case $5(6$ y $6 \mathrm{~m})$ & $1 \mathrm{~m}$ & $\begin{array}{l}\text { No, but he looks } \\
\text { frightened }\end{array}$ & $\begin{array}{l}\text { Psychomotor arrest, unresponsive, } \\
\text { mydriasis, face flushing } \\
\text { Staring, eye and head deviation to R, } \\
\text { arm extension, frightened, apnoea, R } \\
\text { arm and leg rigidity }\end{array}$ & L frontal lesion (polar) \\
\hline Case $6(2$ y $7 \mathrm{~m})$ & $8 \mathrm{~m}$ & No & $\begin{array}{l}\text { Spasms in clusters (upward eye } \\
\text { rotation, flexion of head, and } \\
\text { symmetrical abduction of arms) }\end{array}$ & Cortical thickening of $L$ frontal lobe \\
\hline Case 7 (2 y $2 \mathrm{~m})$ & $6 \mathrm{~m}$ & No & $\begin{array}{l}\text { Spasms in clusters } \\
\text { Psychomotor arrest and fixed gaze }\end{array}$ & $\begin{array}{l}\text { Lesion in L uncus, hippocampus, and } \\
\text { parahippocampal area and mesial } \\
\text { temporo-occipital gyrus }\end{array}$ \\
\hline Case $8(6$ y) & $12 d$ & $\begin{array}{l}\text { Probably yes: he looks } \\
\text { for a support }\end{array}$ & $\begin{array}{l}\text { Hypotonic drop, laughter } \\
\text { Staring, tonic extension of } L \text { arm and leg, } \\
\mathrm{R} \text { arm dystonic with automatisms, } R \\
\text { bicycling, oral automatism and flushing }\end{array}$ & $\begin{array}{l}\text { Large and severe R cortical } \\
\text { disorganisation in fronto-parieto- } \\
\text { temporal lobes } \\
\text { Surgical cavity (previously performed } \\
\text { intervention) }\end{array}$ \\
\hline Case $9(11$ y) & 4 y $7 \mathrm{~m}$ & $\begin{array}{l}\text { Internal tremor, not } \\
\text { better specified }\end{array}$ & $\begin{array}{l}\text { Psychomotor arrest, } R \text { head turning, } R \\
\text { face clonic, responsive } \\
\text { Fixed eyes, pallor, tachycardia, both } \\
\text { arms and legs extension }\end{array}$ & Negative \\
\hline Case $10(7$ y $3 \mathrm{~m})$ & $9 \mathrm{~m}$ & Cephalic sensation & $\begin{array}{l}\text { Bilateral lip corner attraction } \\
\text { Staring, abduction of } L \text { arm, clonic } L \\
\text { arm, eye and sometimes head deviation } \\
\text { to } R, R \text { arm gestural automatisms } \\
\text { Several episodes of epileptic status } \\
\text { Possible generalisation }\end{array}$ & Negative \\
\hline
\end{tabular}

$d$, day; L, left; m, month; MRI, magnetic resonance imaging; $R$, right; $y$, year.

movements. Two patients had normal psychomotor and cognitive development, while two others experienced cognitive deterioration after the seizure onset; three patients had specific cognitive deficits with a normal cognitive level; three had global psychomotor developmental delay, with a severe cognitive defect in one.

\section{Presurgical evaluation}

In all patients a detailed clinical history, a careful description of seizure semiology, and a neurological examination (including a neuropsychological developmental evaluation) were completed, and all previous EEG studies were collected for assessment.

MRI was done following a standardised protocol using a 1.5 T magnet (Philips ACS-NT) including T1 and T2 weighted sequences in the three spatial planes. ${ }^{15}$

Long term video EEG monitoring was done under intensive surveillance in nine of the patients (not case 4), allowing the frequent seizures to be recorded in all the cases.

All patients underwent stereotactic and stereoscopic angiography so as to acquire sufficient information for the surgical intervention and for safe intracerebral electrode implantation.

In six patients we undertook a video-stereo EEG investigation using stereotactically introduced intracerebral electrodes implanted under general anaesthesia. For each patient, 10 to
13 electrodes were implanted unilaterally: diameter $0.8 \mathrm{~mm}$; 5 to 15 leads, each $2 \mathrm{~mm}$ long with an interelectrode distance of $1.5 \mathrm{~mm}$. Video-stereo EEG monitoring was done under the same conditions as the video EEG. Low and high frequency electrical stimulation was applied to localise eloquent cortical areas (for example, motor, somatosensory, or visual areas) and to reproduce the patient's own seizures. ${ }^{16}{ }^{17}$ The stereo EEG study allowed us to determine the origin of ictal discharges and their spread. At the end of each stereo EEG monitoring, three cerebral zones were defined on the basis of the EEG features ${ }^{18}$ :

- the epileptogenic zone-that is, the cortical region in which ictal discharges arise and initially spread;

- the lesional zone-that is, the regions in which absence of background rhythm, electrical depression, continuous slow waves (mainly delta, more or less monomorphic) are found;

- the irritative zone, in which it is possible to find spikes, spike-waves, and polyspike-waves.

\section{Surgical procedure}

Surgical intervention was undertaken on the basis of individual clinical, neuroradiological, and electrical data. The limits of the resection were tailored on the basis of the defined epileptogenic zone, taking into account the limits imposed by the functional anatomy. In the patients 
Table 2 Scalp video EEG results and further choices according to the new classification of the patients (see text)

\begin{tabular}{|c|c|c|c|c|}
\hline & & \multicolumn{2}{|c|}{ Neurophysiological presurgical study: scalp EEG } & \multirow[b]{2}{*}{ Further step } \\
\hline & & Interictal & Ictal & \\
\hline Case 1 & $\begin{array}{l}\text { Video EEG: one } \\
\text { seizure }\end{array}$ & $\begin{array}{l}\text { Normal background activity } \\
L \text { temporal theta diffused to frontal } \\
L \text { temporal S-W }\end{array}$ & $\begin{array}{l}\text { L ant and mid temporal rhythmic } \\
\text { theta activity, temporal S-W diffused } \\
\text { to central area }\end{array}$ & Surgical intervention \\
\hline Case 2 & $\begin{array}{l}\text { Video EEG: two } \\
\text { seizures }\end{array}$ & $\begin{array}{l}\text { Normal background activity } \\
\text { Monomorphic delta in mid- } \\
\text { temporal lead } \\
\text { S, poly S, S-W in R ant and } \\
\text { mid-temporal lobe }\end{array}$ & $\begin{array}{l}\text { Low voltage fast activity predominant } \\
\text { in } \mathrm{R} f-\mathrm{t} \text {, rhythmic slow } \mathrm{S} \text { at } 1 \mathrm{~Hz} \text {, } \\
\text { predominant in } \mathrm{R} f-t\end{array}$ & Surgical intervention \\
\hline Case 3 & $\begin{array}{l}\text { Video EEG: one } \\
\text { seizure }\end{array}$ & $\begin{array}{l}\text { Normal background activity } \\
\text { Spike activity in R f-c-t lobes }\end{array}$ & $\begin{array}{l}\text { Flattening in } \mathrm{R} \text { temporal, diffusing to } \\
f-c \text {, recruiting } \mathrm{S}-\mathrm{W} \text { at } 2 \mathrm{~Hz} \text { in } \mathrm{R} \mathrm{f}-\mathrm{t} \\
\text { region }\end{array}$ & Surgical intervention \\
\hline Case 4 & $\begin{array}{l}\text { Video EEG: no } \\
\text { seizure }\end{array}$ & $\begin{array}{l}\text { Slow } L \text { background activity } \\
\text { Slow waves in } L c-p-t \\
\text { S-W, poly } S-W \text { in } L c-p \text {, } \\
\text { sometimes } R\end{array}$ & - & Surgical intervention \\
\hline \multirow[t]{2}{*}{ Case 5} & $\begin{array}{l}\text { Video EEG: seven } \\
\text { seizures }\end{array}$ & $\begin{array}{l}\text { Slow background activity } \\
\text { Delta activity in L f-c }\end{array}$ & $\begin{array}{l}\text { Irregular delta waves, flattening, low } \\
\text { voltage recruiting fast activity in } \mathrm{L} \text { ant }\end{array}$ & Stereo EEG: 12 ic electrodes in $R \mathrm{f}-\mathrm{t}$ \\
\hline & & S, poly S, poly S-W in L f-c & frontal region & $\begin{array}{l}\text { Seizures: } 9 \text { spontaneous, } 19 \text { with } \\
\text { stimulation }\end{array}$ \\
\hline CoA (case 6) & $\begin{array}{l}\text { Video EEG: three } \\
\text { series of spasms }\end{array}$ & $\begin{array}{l}\text { Absence of background activity } \\
\text { Bilateral } f-c-t \text { delta with diffusion } \\
\text { Focal } S \text { and } S-W \text { on } L f-c \text { region } \\
\text { with diffusion to } R f-c \\
12 \mathrm{~Hz} \text { rhythmic activity }\end{array}$ & $\begin{array}{l}\text { Fast diffused flattening with rhythmic } \\
\text { fast activity and low voltage fast } \\
\text { activity in L frontal region }\end{array}$ & $\begin{array}{l}\text { Stereo EEG: } 11 \text { ic electrodes in L f-c } \\
\text { Seizures: } 12 \text { spontaneous, } 4 \text { with } \\
\text { stimulation }\end{array}$ \\
\hline \multirow[t]{2}{*}{ Case 7} & $\begin{array}{l}\text { Video EEG: four } \\
\text { series of spasms }\end{array}$ & $\begin{array}{l}\text { Slow background activity } \\
\text { Continuous delta activity in L t-o }\end{array}$ & $\begin{array}{l}\text { Diffused low voltage fast activity, } \\
\text { predominant in L post region }\end{array}$ & Stereo EEG: 12 ic electrodes in L t-o-p \\
\hline & & S, S-W, poly S-W in L f-c-t & & $\begin{array}{l}\text { Seizures: } 8 \text { spontaneous, } 5 \text { with } \\
\text { stimulation }\end{array}$ \\
\hline \multirow[t]{2}{*}{ Case 8} & $\begin{array}{l}\text { Video EEG: eight } \\
\text { seizures }\end{array}$ & $\begin{array}{l}\text { Slow background activity } \\
\text { Continuous delta activity in } R \\
\text { hemisphere }\end{array}$ & $\begin{array}{l}\text { Low voltage fast activity in } \mathrm{R} f-c-t \text {, } \\
\text { high voltage slow waves in } t-p \text {, } \\
\text { then recruiting activity }\end{array}$ & Stereo EEG: 11 ic electrodes in R c-p \\
\hline & & $\mathrm{S}, \mathrm{S}-\mathrm{W}$ in $\mathrm{R}$ hemisphere & & $\begin{array}{l}\text { Seizures: } 15 \text { spontaneous, } 4 \text { with } \\
\text { stimulation }\end{array}$ \\
\hline Case 9 & $\begin{array}{l}\text { Video EEG: seven } \\
\text { seizures }\end{array}$ & $\begin{array}{l}\text { Slow } \mathrm{L} \text { background activity } \\
\text { Multifocal L slow } \mathrm{S}\end{array}$ & $\begin{array}{l}\text { Rhythmic slow waves in } L f-c \text {, } \\
\text { diffuse flattening predominant in } \\
L f-c\end{array}$ & $\begin{array}{l}\text { Stereo EEG: } 13 \text { ic electrodes in L f-c } \\
\text { Seizures: } 3 \text { spontaneous, } 10 \text { with } \\
\text { stimulation }\end{array}$ \\
\hline Case 10 & $\begin{array}{l}\text { Video EEG: six } \\
\text { seizures + one } \\
\text { status of minor } \\
\text { motor episodes }\end{array}$ & $\begin{array}{l}\text { Slow background activity } \\
\text { Slow waves in } R \text { frontal } \\
\text { diffusing to } L \text { ant }\end{array}$ & $\begin{array}{l}\text { Diffused attenuation followed by low } \\
\text { voltage fast activity in R f-c-t region, } \\
\text { rapid S-W mainly in R ant frontal } \\
\text { region }\end{array}$ & $\begin{array}{l}\text { Stereo EEG: } 10 \text { ic electrodes in R f-t } \\
\text { Seizures: } 1 \text { spontaneous + status of minor } \\
\text { motor episodes }\end{array}$ \\
\hline
\end{tabular}

ant, anterior; c, central; EEG, electroencephalogram; f, frontal; ic, intracerebral; L, left; o, occipital; p, parietal; post, posterior; R, right; S, spike; S-W, spike and waves; $t$, temporal.

explored by stereo EEG the cortical specimens were analysed in relation to the anatomical location of intracranial electrodes in order to establish the relations among the epileptogenic zone, the anatomical lesion, and the neuropathological data. Lesionectomy was considered complete when neuropathological study revealed no dysplastic tissue at the resection borders.

Postoperative seizure outcome was determined according to the classification proposed by Engel et al. ${ }^{19}$ Follow up ranged from 25 months to 5 years 10 months (mean 3 years 6 months).

A careful routine neuropathological study with immunocytochemical analysis was made on surgical specimens. On the basis of neuropathological investigation three types of dysplasia were recognised: architectural, cytoarchitectural, and Taylor's type of cortical dysplasia; the particular features of these are detailed elsewhere. ${ }^{20}$

\section{RESULTS}

MRI was positive in eight patients, showing a lesion that involved the frontal lobe in two, the temporal lobe in three, two lobes (temporo-occipital and fronto-insular) in two, and three lobes (fronto-parieto-temporal) in one.

The correlative study between seizure characteristics and MRI findings (table 1) allowed us to draw up a list of the patients ordered by degree of anatomical-clinical concordance (from maximum to minimum): maximum concordance was found with the presence of seizures characterised by epigastric sensation, followed by the development of a temporal seizure and evidence of a left temporal pole lesion (case 1); minimum concordance was established for polymorphic seizures, probably of frontal origin, with a negative MRI (case 10).

\section{Long term scalp video EEG}

Interictal and ictal scalp EEG features are detailed in table 2. The background activity was abnormal in seven patients. Interictal abnormalities were localised in two cases, frequently multilobar in four patients, and predominantly on the affected hemisphere with frequent contralateral involvement in four. Ictal phenomena were recorded in nine patients with a mean of four seizures per patient (range one to eight). Initial ictal discharges were well localised in four patients, while a diffuse ictal pattern predominant in a focal area was found in four; one patient (case 5) showed extended delta activity followed by a focalised pattern. The well localised ictal discharges obtained in the three patients (cases 1, 2, and 3 ) who had concordance of electroclinical and MRI evidence allowed surgical intervention after these diagnostic steps had been taken.

Case 4 was submitted to surgical intervention without the long term video recording of seizures because of the patient's young age and severe and rapid cognitive deterioration (mainly in language tasks), and the impossibility of complete 
Table 3 Seizure outcome after surgical intervention tailored on the basis of scalp and stereo EEG explorations

\begin{tabular}{|c|c|c|c|c|c|c|}
\hline & \multicolumn{2}{|l|}{ Stereo EEG } & \multicolumn{2}{|l|}{ Surgery } & \multirow[b]{2}{*}{ Follow up } & \multirow[b]{2}{*}{ Engel class } \\
\hline & Interictal & Ictal (EZ) & Involved structures & Type & & \\
\hline Case 1 & & & $\begin{array}{l}\text { L temporal (pole, } \\
\text { amygdala, } \\
\text { hippocampus, T1 } \\
\rightarrow \mathrm{T} 4 \text { ) }\end{array}$ & $\begin{array}{l}\text { Corticectomy + complete } \\
\text { lesionectomy }\end{array}$ & 2 y $11 \mathrm{~m}$ & la \\
\hline Case 2 & & & $\begin{array}{l}\text { R temporal (pole; } \\
\text { ant T1; ant-mid T2, } \\
\text { T3, T4; mesial) }\end{array}$ & $\begin{array}{l}\text { Corticectomy + complete } \\
\text { lesionectomy }\end{array}$ & 3 y $1 \mathrm{~m}$ & la \\
\hline Case 3 & & & $\begin{array}{l}\text { R temporal (polar, } \\
\text { basal and lateral; } \\
\text { ant hippocampus) }\end{array}$ & $\begin{array}{l}\text { Corticectomy + complete } \\
\text { lesionectomy }\end{array}$ & 5 y $4 \mathrm{~m}$ & la \\
\hline Case 4 & & & $\begin{array}{l}\mathrm{L} \text { triangular and } \\
\text { opercular part of } \mathrm{F} 3\end{array}$ & $\begin{array}{l}\text { Corticectomy + incomplete } \\
\text { lesionectomy }\end{array}$ & 2 y $11 \mathrm{~m}$ & IV \\
\hline Case 5 & $\begin{array}{l}\text { Lesional zone: orbital } \\
\text { and dorsal F2/F3 } \\
\text { Irritative zone: orbital, } \\
\text { F2, F3, ant and } \\
\text { medium cingulated gyrus }\end{array}$ & $\begin{array}{l}\text { Widespread frontal, } \\
\text { mesial and lateral }\end{array}$ & $\begin{array}{l}\text { L frontal (polar, } \\
\text { orbital and dorsal } \\
\text { area) }\end{array}$ & $\begin{array}{l}\text { Corticectomy + complete } \\
\text { lesionectomy }\end{array}$ & 3 y $8 \mathrm{~m}$ & IV \\
\hline Case 6 & $\begin{array}{l}\text { Lesional zone: gyrus } \\
\text { rectus, int and lat F1, } \\
\text { mid ant F2 } \\
\text { Irritative zone: int and } \\
\text { mid F2, orbital gyrus }\end{array}$ & $\begin{array}{l}\text { Global explored } \\
\text { zone except: } \\
\text { precentral gyrus, } \\
\text { posterior Fl and } \\
\text { mesial frontal cortex }\end{array}$ & $\begin{array}{l}\text { L frontal (lateral and } \\
\text { mesial polar, basal } \\
\text { and dorsal F1, F2, } \\
\text { F3) }\end{array}$ & $\begin{array}{l}\text { Corticectomy + complete } \\
\text { lesionectomy }\end{array}$ & 2 y $1 \mathrm{~m}$ & la \\
\hline Case 7 & $\begin{array}{l}\text { Lesional zone: T2, T3, } \\
\text { T4, mid and inf } \\
\text { occipital gyrus } \\
\text { Irritative zone: T1, T2, } \\
\text { mid T4, fusiform gyrus, } \\
\text { hippocampus }\end{array}$ & $\begin{array}{l}\text { Lesion + cuneus and } \\
\text { fusiform gyrus, T3, } \\
\text { T4, posterior } \\
\text { hippocampus }\end{array}$ & $\begin{array}{l}\text { R temporo-occipital } \\
\text { (mesial, basal and } \\
\text { lateral) }\end{array}$ & $\begin{array}{l}\text { Corticectomy + incomplete } \\
\text { lesionectomy }\end{array}$ & 3 y $7 \mathrm{~m}$ & la \\
\hline Case 8 & $\begin{array}{l}\text { Lesional zone: widespread } \\
\text { Irritative zone: widespread }\end{array}$ & Widespread & $\begin{array}{l}R \text { fronto-parieto- } \\
\text { temporal }\end{array}$ & $\begin{array}{l}\text { Second intervention: } \\
\text { incomplete lesionectomy }\end{array}$ & 5 y $10 \mathrm{~m}$ & Ild \\
\hline Case 9 & $\begin{array}{l}\text { Lesional zone: orbital, } \\
\text { dorsal F2, mesial F1 } \\
\text { Irritative zone: F2-F3 } \\
\text { sulcus, dorsal F2, } \\
\text { precentral gyrus }\end{array}$ & $\begin{array}{l}\text { F2-F3 sulcus, F2, } \\
\text { anterior cingular } \\
\text { gyrus }\end{array}$ & L frontal (lateral) & Corticectomy & 2 y $4 \mathrm{~m}$ & la \\
\hline Case 10 & $\begin{array}{l}\text { Lesional and irritative } \\
\text { zones: basal frontal } \\
\text { cortex }\end{array}$ & $\begin{array}{l}\mathrm{R} \text { orbital and gyrus } \\
\text { rectus minor motor } \\
\text { status }\end{array}$ & $\begin{array}{l}\mathrm{R} \text { frontal (polar, } \\
\text { basal, mesial and } \\
\text { lateral) }\end{array}$ & Corticectomy & 4 y $8 \mathrm{~m}$ & lc \\
\hline
\end{tabular}

ant, anterior; EZ, epileptogenic zone; inf, inferior; int, internal; $L$, left; lat, lateral; $R$, right.

resection of the lesion owing to anatomical limitations (insula). The other six patients underwent a stereo EEG exploration to define the epileptic zone (table 2).

\section{Stereo EEG exploration}

On average, 11 intracerebral electrodes per patient (range 10 to 13) were implanted under stereotactic conditions. Chronic video-stereo EEG monitoring allowed us to record at least one spontaneous seizure per patient (rangel to 15, mean 8). Moreover, several seizures were induced by electrical stimulation in five patients. All stereo EEG features are detailed in table 3 .

In the four patients with an MRI evident lesion, the stereo EEG defined lesional zone roughly coincided with neuroimaging data, while in general the irritative zone revealed a larger cerebral involvement.

Of the remaining two with negative MRI, in one case (case 8 ), the lesional and irritative zones were coincident and located in the basal frontal cortex; in the other (case 9), the presence of a specific poly-spike activity cluster in a limited region (fig IC) allowed us to make a diagnosis of Taylor's type cortical dysplasia, subsequently confirmed by histological diagnosis. ${ }^{20}$

The epileptic zone was greater than the neuroradiological lesion in two cases and was widespread in case 8 , in which the MRI showed an extended right hemispheric lesion. The stereo EEG recordings identified the epileptogenic zone in two patients without a neuroradiological lesion.

\section{Surgery}

The surgical intervention (table 3 ) consisted of a corticectomy in two patients with frontal lobe seizures without an MRI lesion, and a lesionectomy plus a tailored corticectomy in the others.

In these latter, the lesionectomy was complete in five patients and incomplete in three (cases 4, 7, and 8). No patient had complications following surgery. One patient (case 7), in whom the resection included all the occipital lobe and the occipito-temporal and occipito-parietal junctions, had a homonymous hemianopia; however, her behaviour shows no difference from before the intervention.

\section{Seizure outcome}

After a mean (SD) follow up of 43 (15) months, seven patients $(70 \%$ of cases) are seizure-free (six in class Ia and one in class Ic). The age of seizure onset, the duration of the epilepsy, and the seizure frequency before the intervention did not show any relation to postoperative seizure-free outcome. Among the patients in whom the seizures persisted after surgery, one patient (case 8) showed noticeable improvement, with one seizure per night. In the other two (cases 4 and 5) seizures are unchanged. Case 4, despite the poor outcome, showed a dramatic improvement in speech function. Postoperative seizure-free outcome was obtained in the two patients in whom the MRI was negative and in five of the eight cases with MRI lesions, including case 7, in whom two lobes were involved. 
A

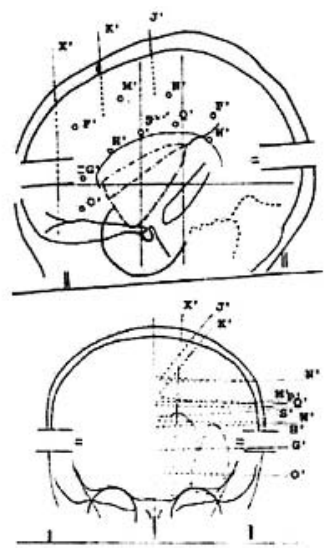

B

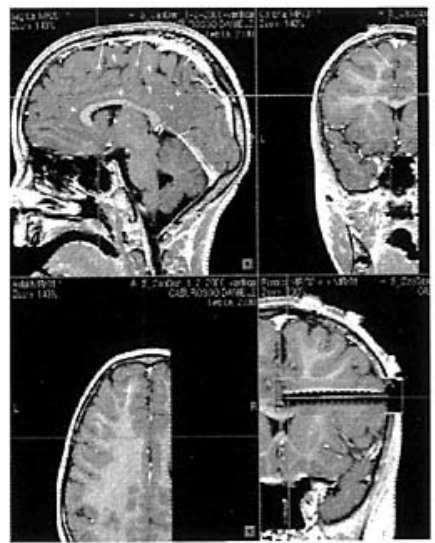

C

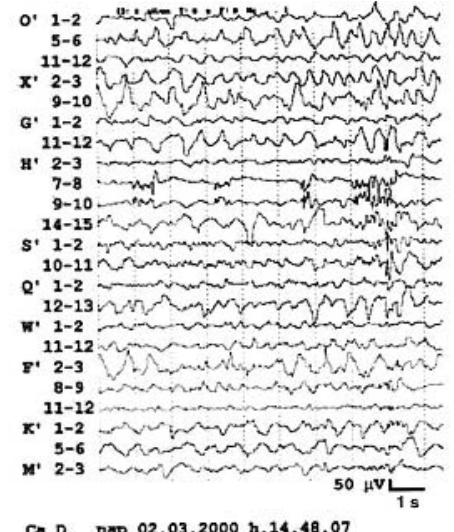

E

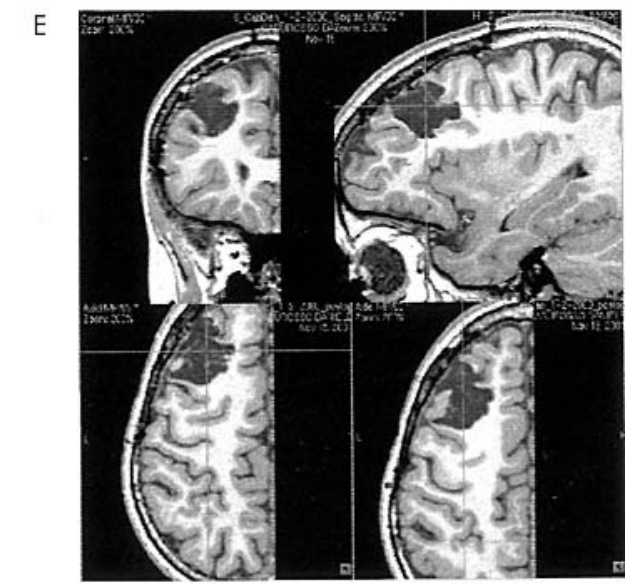

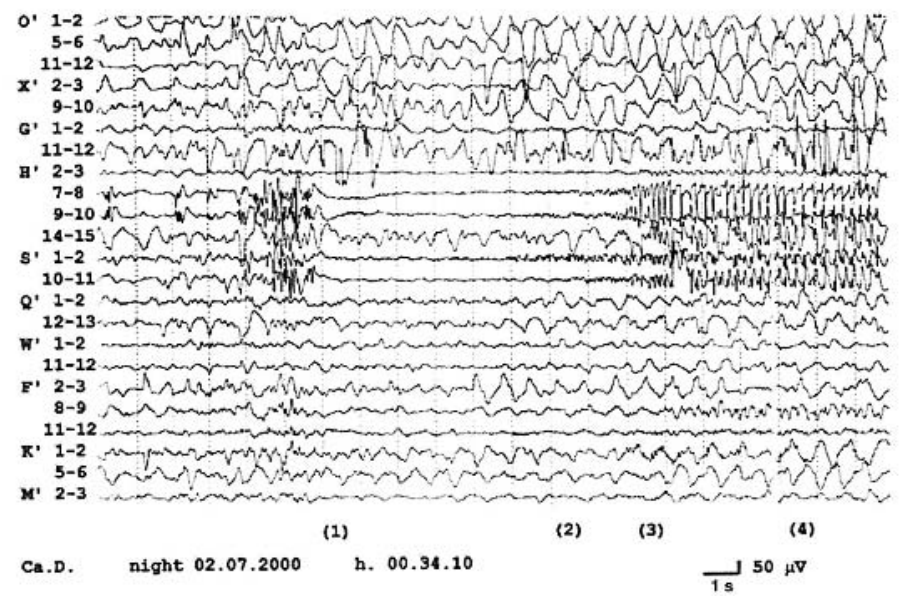

Figure 1 Case 9: stereotactic scheme (A); magnetic resonance images (MRI) with the trajectory of electrode $\mathrm{H}^{\prime}(\mathrm{B})$; interictal trace (C); spontaneous seizure (D); and postoperative MRI (E). (A) The stereotactic scheme shows, in lateral and coronal views, the location of the 13 intracerebral electrodes, all implanted in the left fronto-central region except for two in the parietal lobe. (B) T1 weighted MRI sequences showing the trajectory of the electrode $\mathrm{H}^{\prime}$ : the slice at the bottom shows the real trajectory acquired with the implanted electrodes, while the upper slice makes it possible to appreciate the structures explored as it shows the trajectory without the artefacts caused by the metallic materials. In particular, the mesial leads of this electrode explore the frontal cingulate gyrus, and the lateral leads the lateral cortex of F3; the white square on the trajectory of the electrode identifies the leads from 7 to 10, where the activity of the F2-F3 sulcus is recorded. (C) Nap trace with complete montage in which it is possible to see three burst of ingrading fast activity well localised in the intermediate leads of electrode $\mathrm{H}^{\prime}$; after slowing, the last burst involves the external leads of two adjacent electrodes $\mathrm{S}^{\prime}$ and $\mathrm{F}^{\prime}$, both exploring the frontal convexity. The particular interictal pattern identified on the F2-F3 sulcus allowed us to hypothesise the presence of focal cortical dysplasia, which was confirmed by histological examination. (D) Spontaneous seizure recorded during nocturnal sleep. Clinically, the patient starts groaning at (1) orienting the head to the left; (2) still groaning, he bends moving the left arm apparently trying to grasp the father; (3) the patients looks at the observer without answering his questions; (4) dystonic posturing of the right arm. The seizure will end almost 20 seconds later. Electrically, three seconds before the clinical onset one of the typical burst of fast activity begins in the intermediate leads of $\mathrm{H}^{\prime}$, followed by a spike activity of greater amplitude which involves also the external leads of $\mathrm{S}^{\prime}$ and $\mathrm{F}^{\prime}$ and the mesial leads of $\mathrm{H}^{\prime}$ and $\mathrm{S}^{\prime}$; a few milliseconds before the clinical onset the ictal pattern is characterised by low voltage fast discharge involving all the leads mentioned; this discharge ingrades until (3) after which a rhythmic S-W discharge continues until the end of the fit. (E) Postoperative MRI: the image shows the limited surgical intervention which consisted of excision of the medial and posterior part of F2 and the F2-F3 sulcus.

All the patients operated on for temporal epilepsy had a good outcome and are in class Ia. Seizure outcome has been favourable in three of four patients with frontal epilepsy and in one of the three patients with multilobar involvement. The three with temporal epilepsy and lesions, who were operated on without stereo EEG, became seizure-free. Four of the six patients in whom intracerebral electrodes were implanted had a good outcome, including case 10, who had two seizures in the first year and has now been seizure-free for 4.8 years.

Four of the five patients submitted to a complete lesionectomy are seizure-free. Three patients had an incomplete lesionectomy: in cases 4 and 8 the limits were represented by the anatomical area involved: the insula in case 4 and the central region in case 8 ; in case 7 , incomplete lesion resection was undertaken on the basis of stereo EEG recording which showed that a part of the lesion was not epileptogenic. Among these three patients, only the last is seizure-free.

Cognitive development in all the children improved globally, even in those patients with persistence of seizures. We noticed in particular better attention than before the intervention, a richer vocabulary, and more fluent language.

\section{DISCUSSION}

This study involved a small number of children with drug resistant partial epilepsy, associated with histologically proven focal cortical dysplasia. The number of patients is not substantially different from that in other published studies of children with focal cortical dysplasia, ${ }^{2}$ in surveys including both adults and children with focal cortical 

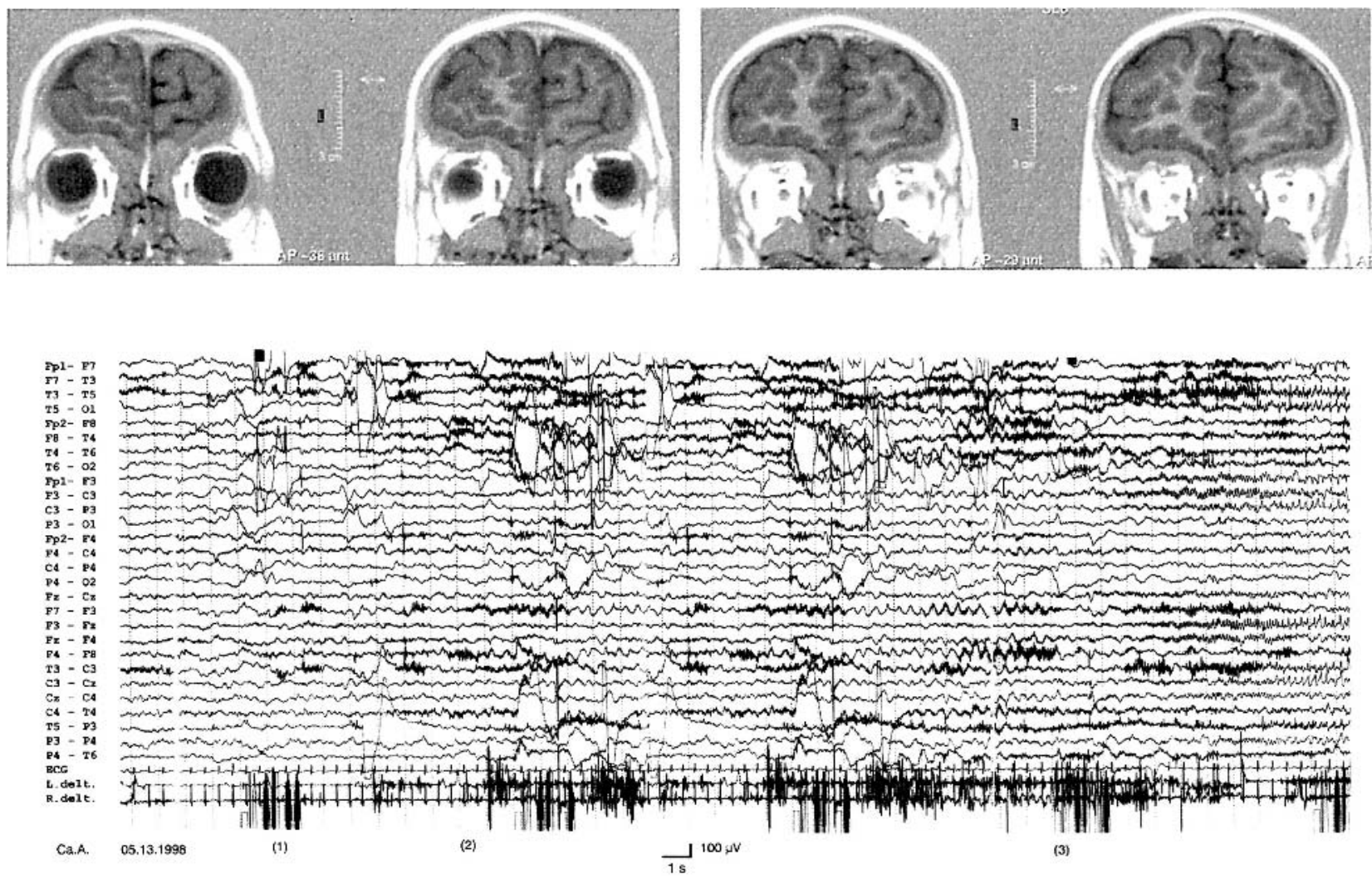

Figure 2 Case 5: presurgical magnetic resonance imaging (MRI) and a spontaneous seizure recorded during sleep on video EEG monitoring. Top: MRI (coronal views in a T1 weighted sequence) showing an abnormality of gyration in the left frontal pole. Clinically the seizure arises one minute after spontaneous awakening: the patient moans, presenting a little jerk of the left arm and extending both limbs at (1); at (2) a slow head and eyes deviation to the right is present together with asymmetrical limb flexion, and at (3) he looks like frightened; almost 15 seconds later the seizure stops without speech disturbance. Bottom: The EEG shows a localised flattening in the left fronto-central leads followed by a rhythmic recruiting delta activity in both fronto-temporal regions; 12 seconds later a fast recruiting activity at $18 \mathrm{~Hz}$ characterises the trace of the left fronto-precentral regions; this activity is also evident in posterior temporal and central regions.

dysplasia, ${ }^{1421}$ or in other studies on resective surgery in children with mixed types of lesion, including focal cortical dysplasia. $^{322} 23$

Though published reports do not always give a detailed description of the localisation and extension of cortical dysplasia in children, the prominence of parietal and central localisation is described in studies by Chassoux et al, ${ }^{14}$ and of multilobar lesions in studies by Hong et al. ${ }^{21}$ Other studies, on the other hand, have shown a frontal predominance 2425 or a heterogeneous distribution. ${ }^{5}$ In our survey, unilobar focal cortical dysplasias are located most often in the frontal lobe (four cases, including the two patients in whom MRI was negative), but the temporal lobe was involved in three cases, thus suggesting that this location could be relatively common in children. In fact, cases with temporal lobe involvement are reported more often in adults. ${ }^{96}$ One possible explanation for this is the lesser impact on children's psychosocial development of temporal lobe epilepsy compared with extratemporal forms, probably linked to a lower frequency of seizures and milder seizure semiology.

As the validation of presurgical strategies and the surgery itself is strongly dependent on the seizure outcome following surgery, in this study we have presented only patients in whom an operation had already been done and whose postoperative follow up had been of substantial duration (at least two years). The overall result in our population is $70 \%$ freedom from seizures. This is not very different from that of Chassoux's study, in which (basing the delimitation of epileptogenic zone on stereo EEG recordings) a seizure-free outcome was achieved in $64 \%$ of adults and children combined. In other series of children operated on for focal cortical dysplasia the percentage of totally cured patients varies from the $30 \%$ of the 20 patients of Polkey, ${ }^{2}$ to the $57 \%$ of 14 patients of Edwards, ${ }^{5} 52 \%$ of Wyllie's cases, ${ }^{3}$ and $41.6 \%$ of Hong's. ${ }^{21}$

As in another series of patients with focal cortical dysplasia, ${ }^{5}$ the general characteristics of onset, duration, and frequency of seizures did not seem to influence the surgical outcome in our group of patients. This is the reason why we attempted to identify and analyse other variables that might play a role in postoperative outcome. In our practice we usually have at our disposal at the time of the patient's first clinical evaluation at least two main types of data: detailed ictal semiology and MRI features. For this reason we decided to organise the study in relation to these two variables.

We therefore ordered the patients in an "anatomicalclinical concordance" list, which strongly influenced the subsequent diagnostic steps and seemed to be related to the surgical outcome. For example, in the three patients with temporal lobe seizures the temporal focal cortical dysplasia was considered the main pathogenic factor; video EEG recordings corroborated this, showing interictal and ictal activities that were well localised over the affected temporal lobe. These three patients are in class Ia, in agreement with many reports of a better seizure-free outcome in patients with temporal lesions than with extratemporal lesions (where surgery was done without an initial invasive study). ${ }^{3} 5$ 27-29 


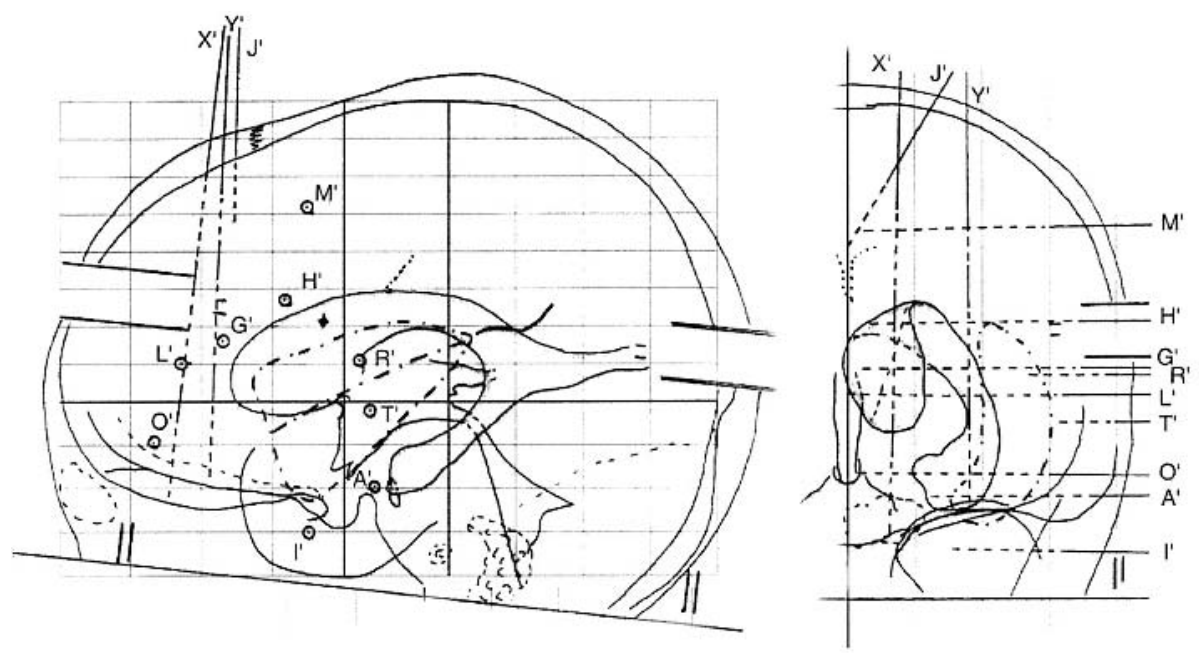

Figure 3 Case 5: stereotactic scheme and spontaneous seizure recorded with depth electrodes. Lateral (upper left) and frontal (upper right) views of the stereotactic scheme show the location of the 12 intracerebral electrodes. Clinically at (1) the patient glances to the left, at (2) he speaks with his mother but, immediately after, he bends its head low and right with staring, (3) he begins to play. Three seconds before (1), the EEG shows the abrupt beginning of a spindle activity at $6 \mathrm{~Hz}$ involving (mainly in the mesial leads) an extensive frontal-basal and anterior region; at (1) a rhythmic sharp activity at $12-14 \mathrm{~Hz}$ is evident in the orbital gyrus (O'7-8); at (2) a low voltage fast activity begins in the same region and rapidly involves almost all the frontal lobe and the temporal pole, showing a greater tonicity in the orbital area $\left(X^{\prime} 1-2\right.$ and $6-7, Y^{\prime} 1-2, O^{\prime} 1-2$ and $\left.7-8\right)$ and external $F 2\left(L^{\prime} 11-12\right.$, probably within the lesion). This activity ends after $7 \mathrm{~s}$, leaving postictal depression in the orbital region and postictal delta activity in the other leads.

On the other hand, a poor degree of anatomical-clinical concordance forced us to consider exploration with intracerebral electrodes in patients with extratemporal epilepsy associated with a lesion on MRI. In these cases, interictal scalp EEG features were not well localised and ictal video EEG monitoring showed at least a bilobar ictal onset discharge. These features precluded a precise definition of the cortical resection but allowed a more detailed implantation strategy. Particularly in the two patients with negative MRI, ictal video EEG recordings represented a very useful source of information for an accurate planning of the stereo EEG exploration.

There is evidence for the value of invasive recording to obtain a better delineation of the epileptogenic zone in cases where extratemporal epilepsy is suspected, with or particularly without positive MRI findings. Some investigators have suggested the use of acute electrocorticography to record and evaluate interictal epileptiform discharges as a measure of the limits of the resection. ${ }^{821}$ Other studies have used chronic invasive exploration (including subdural strips, subdural grids, and depth electrodes) to provide more information about the parts of the cortex functionally linked to the dysplasia. The patients in the studies by Edwards and Wyllie were submitted to an operation after ictal EEG surface recording and invasive study (subdural and epidural grids) in the majority of cases. A few of Edwards' cases $^{5}$ and $20 \%$ of Polkey's ${ }^{2}$ were studied with chronic intracerebral electrode implantation; in Hong's study, chronic subdural electrodes were used. ${ }^{21}$ Only one study described the results obtained after stereo EEG recording. ${ }^{14}$

In our group of patients the extent of cortical excision was defined mainly on the basis of ictal clinical and electrographic data recorded during the chronic stereo EEG procedure-always considering the localising indications provided by the MRI study. As a general statement, in our cases intralesional electrodes were often the sites of the ictal 
onset discharges, but ictal patterns might vary from one seizure to another, and very often lesional and non-lesional electrodes were involved simultaneously, as described in a previous study in non-paediatric patients. ${ }^{30}$ Tailoring surgical excision on this basis led to a seizure-free outcome of four of the six patients explored.

Stereo EEG recordings played an important role in clarifying the relations between the dysplastic area and the apparently normal cortex in the organisation of the epileptogenic network. Although recent reports on histological specimens prove that cortical malformation is intrinsically epileptic, ${ }^{31} 32$ some clinical and EEG findings ${ }^{28-11}$ suggest that the cortical region in which ictal discharges arise and primitively spread is not strictly coincident with the dysplasia, or that it is larger than the lesion.

We also found that the onset of spontaneous and induced seizures involves electrodes inserted outside the dysplastic lesion; these data were confirmed by histological examination, in which a part of the surgical specimen was histologically normal. Our cases confirm on the one hand that the epileptogenic zone may involve histologically proven normal tissue, and on the other, that incomplete lesion resection with preservation of part of the malformed tissue (proven to be non-epileptogenic) could give a good outcome. An example of this possibility is given by our case 7, cured after incomplete lesionectomy of a bilobar focal cortical dysplasia, and also by four of 10 patients in Chassoux's study who were seizure-free despite an incomplete lesionectomy. Dysplastic cortex can, in fact, participate in the organisation of function along with normal cortex, ${ }^{33}$ which is supported by recent data acquired using functional MRI, ${ }^{34}$ and defining the actual extension of the epileptogenic area by ictal invasive recordings can help to spare part of the dysplastic cortex. Nevertheless, the possibility of curing patients with an incomplete lesionectomy remains the exception rather than the rule, and we agree with those investigators who maintain that a complete or major excision of both the MRI visible lesion and the cortical areas displaying ictal activity leads to the best results. ${ }^{4}{ }^{14}$

Concerning the localisation of the epileptogenic zone, we emphasise the role of stereo EEG in rendering seizure-free three of four patients with frontal lobe epilepsy, among whom there were two with negative MRI. Considering that surgical results in frontal lobe epilepsy are less favourable than in temporal lobe epilepsy, and that surgical series have reported a seizure-free outcome in about $60-65 \%$ of cases, ${ }^{35-37}$ our $75 \%$ of cured patients with a frontal excision should be regarded as an encouraging result. This finding could suggest that there may be a correlation between the presence of focal cortical dysplasia and a good outcome; in fact the three cited series of patients with frontal lobe epilepsy are composed of subjects with various types of lesion and also of patients without any lesion. However, the possibility of exploring cerebral areas infolded in a sulcus when using intracerebral electrodes (fig 1) could have contributed to a better delineation of the epileptogenic zone. Our case 5 shows the difficulty in finding a technique that can guarantee a completely successful surgical outcome, despite good location of the epileptogenic lesion and corticectomy and lesionectomy (figs 2 and 3). According to Sisodyia ${ }^{12}$ and Jayakar et al,,$^{13}$ some cases are not seizure-free despite complete resection, probably because of the presence in these cases of more than one epileptogenic focus, which may become evident after the excision of the first focus. As the great majority of patients show cognitive developmental delay-resulting from the lesion itself, the repetitive seizures, and the need for powerful drugs - the aim of surgery in these children should not only be relief from severe epilepsy but also improvement in developmental progress. ${ }^{38}$ We believe our data can help in confirming this possibility, considering that our treated patients showed clinically evident psychosocial and cognitive improvement.

\section{Authors' affiliations \\ S Francione, L Tassi, F Cardinale, R Mai, G Lo Russo, *C Munari,} Epilepsy Surgery Centre "C Munari", Department of Neuroscience, Niguarda Hospital, Milan, Italy

P Vigliano, Department of Child Neuropsychiatry, University of Turin, Turin, Italy

*In memoriam

Competing interests: none declared

\section{REFERENCES}

1 Brodtkorb F, Nilsen G, Smevik O, et al. Epilepsy and anomalies of neuronal migration: MRI and clinical aspects. Acta Neurol Scand 1992:86:24-32.

2 Polkey CE. Cortical dysplasia: resective surgery in children. In: Guerrini R, Andermann F, Canapicchi R, et al, eds. Dysplasias of cerebral cortex and epilepsy. Philadelphia: Lippincot-Raven, 1996:435-9.

3 Wyllie E, Comair YG, Kotagal P, et al. Seizure outcome after epilepsy surgery in children and adolescents. Ann Neurol 1998;44:740-8.

4 Palmini A, Gambardella A, Andermann F, et al. Operative strategies for patients with cortical dysplastic lesions and intractable epilepsy. Epilepsia 1994:35:S57-71.

5 Edwards JC, Wyllie E, Ruggeri PM, et al. Seizure outcome after surgery for epilepsy due to malformation of cortical development. Neurology 2000;55:1110-14.

6 Kuzniecky R. Magnetic resonance imaging in developmental disorders of cerebral cortex. Epilepsia 1994;35:S44-56.

7 Kuzniecky R, Murro A, King D, et al. Magnetic resonance imaging in childhood intractable epilepsy: pathologic correlations. Neurology 1993:43:681-7.

8 Palmini A, Gambardella A, Andermann F, et al. Intrinsic epileptogenicity of human dysplastic cortex as suggested by corticography and clinical results. Ann Neurol 1995;37:476-87.

9 Raymond A, Fish D, Sisodiya S, et al. Abnormalities of gyration, heterotopias tuberous sclerosis, focal cortical dysplasia, microdysgenesis, dysembryoplastic neuroepithelial tumor and dysgenesis of the archicortex in epilepsy: clinical, EEG and neuroimaging features in 100 adult patients. Brain 1995: 118:629-60.

10 Kuzniecky R, Morawetz R, Faught E, et al. Frontal and central lobe focal dysplasia: clinical EEG and imaging features. Dev Med Child Neurol 1995;37:159-66.

11 Olivier A, Andermann F, Palmini A, et al. Surgical treatment of the cortical dysplasias. In: Guerrini R, Andermann F, Canapicchi R, et al, eds. Dysplasias of cerebral cortex and epilepsy. Philadelphia: Lippincot-Raven, 1996:351-66.

12 Sisodiya SM. Surgery for malformations of cortical development causing epilepsy. Brain 2000;123:1075-91.

13 Jayakar $\mathbf{P}$, Duchowny $M$, Alvarez L, et al. Intraictal activation in the neocortex: a marker of the epileptogenic region. Epilepsia 1994;35:489-94.

14 Chassoux F, Devaux B, Landre E, et al. Stereoelectroencephalography in focal cortical dysplasia: a 3D approach to delineating the dysplastic cortex. Brain 2000; 123:1733-51.

15 Colombo N, Tassi L. Prognostic value of MRI. Epilepsia 2000;41:89-90.

16 Kahane P, Francione S, Tassi L, et al. Results of epilepsy surgery: criteria for validation of presurgical investigations. Boll Lega It Epil 1994;86/ 87:405-19.

17 Munari C, Hoffmann D, Francione S, et al. Stereo-electroencephalography methodology: advantages and limits. Acta Neurol Scand 1994:S152:56-67.

18 Bancaud J, Talairach J, Bonis A, et al. La stéréo-électro-encéphalographie dans I'épilepsie. Informations neuro-physio-pathologiques apportées par l'investigation fonctionnelle stéréotaxique. Paris: Masson, 1965.

19 Engel J, Van Ness P, Rasmussen T, et al. Outcome with respect to epileptic seizures. In: Engel J, ed. Surgical treatment of the epilepsies, 2nd ed. New York: Raven Press, 1993:609-21.

20 Tassi L, Colombo N, Gabelli R, et al. Focal cortical dysplasia: neuropathologic subtypes, EEG, neuroimaging and surgical outcome. Brain 2002; 125:1719-32.

21 Hong SC, Kang KS, Seo DW, et al. Surgical treatment of intractable epilepsy accompanying cortical dysplasia. J Neurosurg 2000;93:766-73.

22 Fish DR, Smith SJ, Quesney LF, et al. Surgical treatment of children with medically intractable frontal and temporal lobe epilepsy: results and highlights of 40 years' experience. Epilepsia 1993;34:244-7.

23 Paolicchi J, Dean $P$, Jayakar $P$, et al. Outcome of focal resection in preadolescent children with intractable partial epilepsy. Epilepsia 1996;37:210.

24 Palmini A, Andermann F, Olivier A, et al. Focal neuronal migration disorders and intractable partial epilepsy: a study of 30 patients [review]. Ann Neurol 1991;30:741-9.

25 Kuzniecky R. Neuroimaging in pediatric epilepsy. Epilepsia 1996:37:S10-21. 
26 Brännströme T, Silfvenius $\mathrm{H}$, Olivecrona $M$. The range of disorders of cortical organization in surgically treated epilepsy patients. In: Guerrini R, Andermann F, Canapicchi R, et al, eds. Dysplasias of cerebral cortex and epilepsy. Philadelphia: Lippincot-Raven, 1996:57-64.

27 Brockhaus A, Helger CE. Complex partial seizures of temporal lobe origin in children of different age groups. Epilepsia 1995;36:1173-81.

28 Spencer SS. Progress in epilepsy research: long-term outcome after epilepsy surgery. Epilepsia 1996;37:807-13.

29 Cossu M, Tassi L, Cardinale F, et al. Temporal lobe epilepsy: a noninvasive presurgical approach. Epilepsia 2000;41:21.

30 Munari C, Francione F, Kahane P, et al. Usefulness of stereo-EEG investigations in partial epilepsy associated with cortical dysplastic lesions and gray matter heterotopia. In: Guerrini R, Andermann F, Canapicchi R, et al, eds. Dysplasias of cerebral cortex and epilepsy. Philadelphia: LippincotRaven, 1996:383-94

31 Spreafico R, Battaglia G, Arcelli P, et al. Cortical dysplasia: an immunocytochemical study of three patients. Neurology 1998;50:27-36.
32 Duchowny $M$, Jayakar $P$, Levin $B$. Aberrant neural circuits in malformations of cortical development and focal dysplasia. Neurology 2000;55:423-8.

33 Duchowny MS, Resnick TJ, Alvarez LA, et al. Focal resection for malignant partial seizures in children. Neurology 1996;40:980-4.

34 Innocenti GM, Maeder PH, Knyazeva MG, et al. Functional activation of microgyric visual cortex in human. Ann Neurol 2001;50:672-6.

35 Laskovitz DT, Sperling MR, French JA, et al. The syndrome of frontal lobe epilepsy: characteristics and surgical management. Neurology 1995:45:780-7

36 Jobst BC, Siegel AM, Thadani VM, et al. Intractable seizures of frontal lobe origin: clinical characteristics, localizing signs, and results of surgery. Epilepsia 2000;41:1139-52.

37 Mosewich RK, So EL, O'Brien TJ, et al. Factors predictive of the outcome of frontal lobe epilepsy surgery. Epilepsia 2000;41:843-9.

38 Wyllie E. Surgical treatment of epilepsy in pediatric patients. Can J Neurol Sci 2000;27:106-10.

\section{NEUROLOGICAL PICTURE}

\section{Knitting artifact}

A rtifacts are recorded signals that are non-cerebral in origin ${ }^{1}$ and may be either physiological, due to body activities, or non-physiological, which arise from either external electrical interference or internal electrical malfunctioning of the recording system.

We describe here the first known case of artifact generation resulting from a patient knitting during a video EEG recording. In the figure, apparent spikes or sharply contoured slow waves are seen phase reversing at $\mathrm{T} 3$ and $\mathrm{T} 4$. On video, these changes are seen to coincide with the patient transferring a stitch from one knitting needle to the other. These sharp transients were also seen on separate occasions at $\mathrm{Cz}, \mathrm{P} 3, \mathrm{~T} 4$, and other derivations.

No eye blinks or gross movements of the body by the patient were seen during these changes. One hypothesis might be that the wool being knitted by the patient causes a build up of static electricity either on the knitting needles or on the wool itself. During the transfer of the stitch from one needle to the other, the tapping of the needles together may cause the release of this static electricity and allow it be recorded on the EEG.
E S Papathanasiou, P Myrianthopoulou, S S Papacostas Department of Clinical Neurophysiology, The Cyprus Institute of Neurology \& Genetics, Nicosia, Cyprus

Correspondence to: E Papathanasiou, Department of Clinical Neurosciences, The Cyprus Institute of Neurology \& Genetics, 6 International Airport Avenue, P.O. Box 23462, Nicosia 1683, Cyprus; neurophy@cing.ac.cy

\section{References}

1 Fisch BJ (ed). Spehlmann's EEG primer, 2nd edn. Amsterdam, Oxford: Elsevier publications, 1991:107-26.

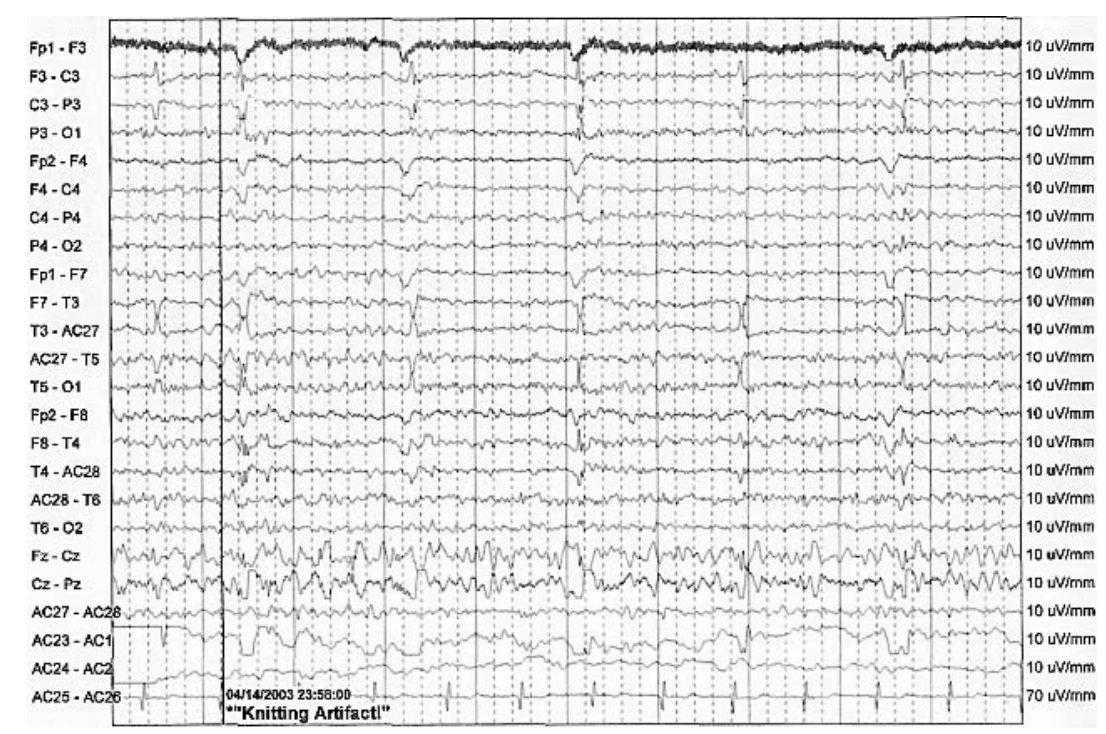

EEG showing knitting artifact, representing as spikes with a maximum at T3 and T5. AC27 and AC28 represent the left and right sphenoidal electrodes, respectively. AC23 and AC24 are the left upper canthus and right lower canthus electrodes, respectively, for EOG recording. The AC25-AC26 derivation is ECG recording. 